\title{
Author Correction: Increasing neurogenesis refines hippocampal activity rejuvenating navigational learning strategies and contextual memory throughout life
}

\author{
Gabriel Berdugo-Vega, Gonzalo Arias-Gil, Adrian López-Fernández, Benedetta Artegiani, \\ Joanna M. Wasielewska (D), Chi-Chieh Lee, Michael T. Lippert, Gerd Kempermann, Kentaroh Takagaki (D) \& \\ Federico Calegari
}

Correction to Nature Communications https://doi.org/10.1038/s41467-019-14026-z, published online 09 January 2020.

The original version of this Article contained errors in the author affiliations. Affiliation 2 incorrectly read Laboratory of Integrative Neuroscience, Institute of Biology, Otto-von-Guericke University Magdeburg, Leipziger Strasse 44, 39120 Magdeburg, Germany. This has been corrected to Leibniz Institute for Neurobiology, Magdeburg, Brenneckestr. 6, 39118 Magdeburg, Germany. Also, the affiliation of Kentaroh Takagaki with Laboratory in Sensory Physiology, Institute of Biology, Otto-von-Guericke University Magdeburg, Leipziger Strasse 44, 39120, Magdeburg, Germany was inadvertently omitted.

These have now been corrected in both the PDF and HTML versions of the Article.

Published online: 25 February 2020

\footnotetext{
(c) (i) Open Access This article is licensed under a Creative Commons Attribution 4.0 International License, which permits use, sharing, adaptation, distribution and reproduction in any medium or format, as long as you give appropriate credit to the original author(s) and the source, provide a link to the Creative Commons license, and indicate if changes were made. The images or other third party material in this article are included in the article's Creative Commons license, unless indicated otherwise in a credit line to the material. If material is not included in the article's Creative Commons license and your intended use is not permitted by statutory regulation or exceeds the permitted use, you will need to obtain permission directly from the copyright holder. To view a copy of this license, visit http://creativecommons.org/licenses/by/4.0/.
}

(C) The Author(s) 2020 